\title{
LIBERALISMO VS. COMUNITARISMO* (JOHN RAWLS: UNA CONCEPCIÓN POLÍTICA DEL BIEN)
}

ohn Rawls, al retomar el tema de la relación entre lo justo (Tò díkaıov, right) y lo bueno (Tò àyatóv, good) en uno de sus últimos artículos ${ }^{2}$, ha vuelto a centrar la reflexión filosófico-moral en uno de los viejos temas ligados al origen mismo de esta reflexión: la congruencia entre lo bueno y lo justo ${ }^{3}$, o, lo que es lo mismo, la posibilidad de hacer compatible una teoría de la justicia con una concepción del bien y de legitimar el surgimiento de virtudes políticas como la tolerancia, la razonabilidad, el sentido de equidad, que son las bases de la cooperación social y por tanto de una sociedad justa y bien ordenada.

Rawls es consciente de la necesidad de esa compatibilidad si se quiere formular una concepción pública de la justicia que proporcione la estructura normativa para las instituciones sociales básicas de una democracia constitucional donde los individuos, que son parte integrante de ella, no solamente admiten la necesidad de un ordenamiento normativo de la misma, sino que también tienen una concepción del bien, que desean desarrollar y realizar dentro de dicha sociedad ${ }^{4}$.

${ }^{*}$ Quiero expresar mi agradecimiento a Javier de Lucas por su lectura, consejos y sugerencias que han contribuido, sin duda ninguna, a mejorar la primera redacción de este trabajo, que fue presentada en el X Congrès de Filosofia al País Valencià.

${ }^{2}$ J. Rawls, «The Priority of Right and Ideas of the Good», en: Philosophy and Public Affairs, vol. 17, n. ${ }^{\circ} 4,1988$, págs. 251-77; ver también: A Theory of Justice, Oxford, Blackwell, 1972 (Trad. cast., Teoría de la Justicia, F.C.E., 1979); «Justice as Fairness: Political Not Metaphysical», en: Philosophy and Publics Affairs, vol. 14, n. ${ }^{\circ} 3,1985$, págs. 223-51, «The Idea of an Overlapping Consensus», en: Oxford Journal of Legal Studies, vol. 7, nº . 1, 1987, pág. 25. (Estos artículos se citarán, respectivamente: P.R.I.G.; T.J.; J.F.P.M.; I.O.C).

${ }^{3} \mathrm{Cfr}$. Gilberto Gutiérrez, «La congruencia entre lo bueno y lo justo. Sobre la racionalidad en

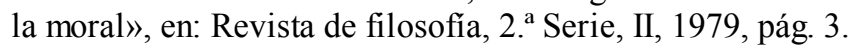

${ }^{4}$ Sobre este punto, ver M $M^{\text {a }}$ Pilar González Altable, «John Rawls: una concepción pública de justicia para una sociedad pluralista y democrática», en: Quaderns, 
La concepción rawlsiana, al proporcionar el marco normativo necesario para que la congruencia entre lo justo y lo bueno sea posible, abre una nueva perspectiva para el pensamiento liberal contemporáneo al separarlo de consideraciones neoconservadoras o libertarias como las de Hayek, Nozick y otros, y al colocarlo en un terreno donde los planteamientos más ligados a un liberalismo exclusivamente económico pasan a un segundo lugar ${ }^{4}$.

En este sentido Rawls ha abierto un nuevo punto de partida para la reflexión político-liberal cuyo objetivo central es hacer compatible el individualismo con una valoración de la sociedad, de la cooperación social, y donde libertad e igualdad no sean conceptos opuestos, sino que la afirmación del primero lleve a la realización del segundo.

Por eso no es de extrañar que el liberalismo de Rawls haya suscitado una inmensa literatura tanto a favor como en contra y que la polémica esté servida sobre todo desde la línea de pensamiento inaugurada por comunitaristas como A. MacIntyre, M. J. Sandel, Ch. Taylor $^{5}$ que pretenden mostrar la incompatibilidad de las afirmaciones básicas del liberalismo, como son la defensa de los derechos básicos del individuo, la pluralidad de concepciones del bien y la prioridad de lo justo sobre lo bueno, con la necesidad de establecer prioritariamente una concepción comprehensiva del bien, cuyo núcleo sea el establecimiento de la comunidad como el bien básico, el fin último de la vida buena, y sin la cual la justificación de principios prácticos generales es imposible.

El adoptar una postura u otra indudablemente nos llevará a estructurar un modelo de sociedad distinto y una teoría política con una fundamentación ética distinta.

Ante este panorama de separación de posturas la teoría normativa de Rawls se presenta como un intento de elaborar una teoría capaz

vol. 18, 1991, págs. 43-45; y John Rawls: Una concepción política y liberal de la Justicia, La Coruña. Novo Século, 1993.

${ }^{4}$ Sobre este punto son muy interesantes los trabajos de: Javier Muguerza. «Entre el liberalismo y el libertarismo. Reflexiones desde la ética», en: Zona Abierta, vol. 30, 1984, págs. 1-62; Brian Barry, The Liberal Theory of Justice, Oxford, Blackwell, 1975: Chantal Mouffe, «Rawls: Political Philosophy Without Politics» en: David Rasmussen (ed.), Universalism vs. Communitarianism, Cambridge (Mass.), The M.I.T. Press, 1990, págs. 217-37.

${ }^{5}$ A. MacIntyre, After Virtue, University of Notre Dame Press, 1984, (trad. cast. Tras la virtud, Barcelona, Crítica, 1987): Whose Justice? Which Rationality?, London, Duckworth, 1988; M. Sandel, Liberalism and the Limits of Justice, Cambridge University Press, 1981 «Justice and Good», en: M. Sandel (ed.), Liberalism and its Critics, Oxford, Blackwell, 1984, págs. 159-177; Ch. Taylor, «Hegel: History and Politics», en: M. Sandel (ed.). ibid. págs. 177-200; Sources of the Self. The Making of Modern Identity, Cambridge (Mass.), Harvard University Press. 1989. 
de justificar un conjunto de principios prácticos subyacentes a una concepción política de la sociedad que incorpore una concepción del bien no moral sino política. Una teoría cuyo objetivo central es posibilitar la realización del bien moral de cada individuo, no sólo como ente particular, sino también como miembro de una colectividad, y sin intentar definir a priori la «buena comunidad».

Ello es, precisamente, lo que me ha llevado, en el presente trabajo, a analizar y exponer en primer lugar la concepción del bien que Rawls elabora como parte integrante de su concepción política de «justicia como equidad», y en segundo lugar a examinar hasta qué punto son acertadas o no las críticas comunitaristas a Rawls y en general al neoliberalismo.

Uno de los análisis más sugerentes actualmente sobre la relación entre los conceptos de lo justo y lo bueno es la concepción política de justicia elaborada por Rawls, donde la bondad como racionalidad juega un papel importante.

A este respecto comenzaremos el análisis con un texto de Rawls bastante significativo:

«la idea de la prioridad de lo justo (right) es un elemento esencial en lo que he llamado liberalismo político y tiene un papel central en justicia como equidad como una interpretación de esa visión (...). Intentaré cambiar esas y otras ideas erróneas sobre lo que la prioridad de lo justo significa esbozando su conexión con cinco ideas bien fundadas en justicia como equidad: (1) la idea de bondad como racionalidad, (2) la idea de los bienes primarios, (3) la idea de permitir concepciones comprehensivas del bien, (4) la idea de las virtudes políticas, y (5) la idea del bien de una sociedad (política) bien ordenada $\rangle^{6}$.

La concepción política de justicia rawlsiana no determina lo que es lo bueno, pero tampoco se ve condicionada a priori por una concepción comprehensiva del bien, siendo su objetivo central crear el marco normativo necesario para el desarrollo de la libertad. La concepción política de justicia de Rawls pretende ante todo justificar unos principios prácticos generales que garanticen las libertades y derechos básicos de los individuos en cuanto que son personas individuales y ciudadanos de una sociedad bien ordenada.

Rawls no trata en ningún momento de establecer o definir cuál es el valor fundamental de la vida humana, aquello que constituye la vida buena, sino de crear un marco normativo para una sociedad,

${ }^{6}$ P.R.I.G., pág. 251. 
vista como una empresa cooperativa para el beneficio de todos los que la componen, sin que por ello haya un rechazo de las concepciones morales y filosóficas globales que forman parte de la concepción del bien de cada individuo como personas morales.

Ahora bien, para comprender la concepción del bien planteada por Rawls, tenemos previamente que analizar su liberalismo político.

El liberalismo político rawlsiano y el modelo de sociedad que éste sustenta se caracteriza, ante todo, por crear un espacio común donde una pluralidad de formas de vida con distintas concepciones del bien puedan coexistir, facilitando así la unión entre pluralidad, cultura, libertad individual, racionalidad pública y racionalidad individual.

Rawls desarrolla un liberalismo donde la prioridad de lo justo sobre lo bueno facilita la incorporación de un fuerte principio de libertad negativa, posibilitando así, por un lado, el reconocimiento de la pluralidad, y por otro, estableciendo el alcance y límites del poder del estado. El estado está para garantizar y posibilitar el desarrollo de derechos políticos y civiles de los individuos promoviendo la sociedad como una empresa cooperativa para el beneficio de todos.

De esta forma, si seguimos el razonamiento rawlsiano a lo largo de toda su obra, y sobre todo en sus últimos artículos ${ }^{7}$, se aprecia perfectamente que el objetivo central de su argumentación estriba en fundamentar una concepción política de la justicia que soporte una concepción liberal del estado, pero en ningún momento intenta proporcionar una concepción sustantiva del bien.

Una concepción normativa de la política, según Rawls, no debe señalar cuáles son los fines últimos del hombre ni en qué consiste su felicidad. Esto es algo que cada individuo debe determinar por sí mismo y la concepción pública de justicia debe crear el marco adecuado para que cada individuo pueda intentar la realización de sus fines particulares, sean cuales sean. Ello no implica que esta concepción no lleve aparejada una concepción de las virtudes políticas necesarias para un mejor desarrollo de la cooperación social y una noción del bien, cuya característica esencial es que pueda ser compartida por todos los individuos que componen la unidad social, independientemente de sus concepciones del bien de un alcance más comprehensivo.

Por tanto, una concepción política según Rawls:

«...debe dibujarse sobre varias ideas de bien. La cuestión es: ¿bajo qué restricciones puede el liberalismo político hacer esto?» ${ }^{8}$.

\footnotetext{
${ }^{7}$ Ver nota (1).

${ }^{8}$ P.R.I.G., pág. 253.
} 
La principal restricción, en la estructura argumentativa de Rawls, presupone la prioridad de lo justo sobre el bien, lo que únicamente significa que las ideas del bien para ser plausibles deben respetar los límites de la concepción política de la justicia. Esta concepción supone: 1) que puede ser compartida por ciudadanos libres e iguales y 2) que no presume una concepción comprehensiva del bien completamente particular?.

La concepción del bien aceptable para una concepción política de la justicia concebida como un liberalismo político tendrá, por tanto, unas características propias que la harán diferente de una concepción comprehensiva del bien, tal como veremos a continuación.

Primeramente Rawls denomina a su concepción del bien bondad como racionalidad. Esta concepción se construye sobre dos ideas básicas: a) los miembros de una sociedad democrática tienen al menos una idea intuitiva de cuál es su plan racional de vida y a la luz de él ordenan todos sus recursos y esfuerzos; b) una concepción política de justicia, para ser factible y servir de base justificativa para los ciudadanos, debe incluir la vida humana y el cumplimiento de las necesidades y propósitos de cada individuo como un bien general, y situar la racionalidad como un principio básico de la organización política y social ${ }^{10}$.

Bondad como racionalidad es una concepción política que en conjunción con otras ideas como la idea política de persona ${ }^{11}$ cumple dos funciones dentro de la concepción política de justicia: a) nos ayuda a identificar una lista de bienes primarios factible y b) nos capacita para poder especificar la motivación de las partes en la posición original y explicar por qué dicha motivación es racional.

Esta parte de la teoría es la que Rawls denomina la teoría escueta (thin) del bien cuyo contenido lo componen el conjunto de bienes primarios $^{12}$.

${ }^{9}$ P.R.I.G., pág. 263.

${ }^{10}$ P.R.I.G., págs. 254 y ss. Ver también: T. J. cap. VII, pero teniendo en cuenta que las ideas aportadas en P.R.I.G. suponen un avance con respecto al análisis del bien que lleva a cabo en dicho capítulo; J.F.P.M. sección I.

${ }^{11}$ Sobre este punto, ver nota (3).

12 «La lista de los bienes primarios básicos (...) tiene cinco encabezamientos: (1) derechos y libertades básicas de los que una lista puede también ser dada; (2) libertad de movimiento y libre elección de ocupación junto con un haz de diversas oportunidades; (3) posibilidades y prerrogativas de oficios y posiciones de responsabilidad en las instituciones políticas y económicas de la estructura básica; (4) ingresos y riqueza (5) las bases sociales del autorrespeto. Esta lista incluye las principales características de las instituciones, esto es, derechos y libertades básicas, oportunidades institucionales, y prerrogativas de oficio y posición junto con ingresos y riqueza. Las bases sociales del autorrespeto son explicadas en términos institucionales completados con las características de la cultura política pública tales como el reconocimiento público y la aceptación de principios de justicia» (P.R.I.G., pág. 257) 
Estos bienes son los valores comunes, los valores insertos en la cultura pública de las sociedades democráticas contemporáneas y cuya distribución es precisamente la que regulará los principios de justicia.

La teoría escueta del bien presupone la autonomía racional de las partes, que les lleva a desear la mayor cantidad posible de los bienes básicos cuya distribución es objeto de la estructura básica de la sociedad y por tanto debe ser regulada por una concepción pública de justicia.

Así bondad como racionalidad no es, para Rawls, una doctrina comprehensiva del bien humano, sino parte de una concepción política de justicia, vista como una forma de liberalismo político que proporciona los bienes comunes que toda democracia constitucional trata de distribuir.

El liberalismo político busca ante todo una idea de ventaja racional dentro de una concepción política que sea independiente de una doctrina comprehensiva particular y desde aquí ser el centro de un «consenso por solapamiento» (overlapping consensus), lo que le permitirá alcanzar lo que ha de contar como una demanda apropiada.

En justicia como equidad la concepción de los bienes primarios dirige este problema político-práctico y la pieza clave es que los ciudadanos, aunque no afirmen la misma concepción comprehensiva completa en todos sus fines últimos y lealtades, satisfacen dos condiciones para una idea compartida de ventaja racional: 1) afirman la misma concepción de sí mismos como personas libres e iguales; y 2) sus concepciones del bien y las doctrinas religiosas y filosóficas afines, aunque distintas unas de otras, requieren para su desarrollo los mismos bienes básicos, esto es, las mismas oportunidades, derechos, libertades, así como los mismos medios económicos -ingresos y riqueza-, todo lo que en definitiva está asegurado por las mismas bases del autorrespeto. Esos bienes son cosas que los ciudadanos necesitan como personas libres e iguales, y las demandas sobre ellos son vistas como demandas absolutamente apropiadas ${ }^{13}$.

Como vemos, en Rawls hay una definición institucional del bien que hace que éste sea objeto de una concepción política de justicia y no de una concepción moral del mismo. Ello supone un avance con respecto a doctrinas utilitaristas, en cuanto doctrinas comprehensivas, y también con respecto a planteamientos comunitaristas, dado que ninguna concepción comprehensiva del bien es aceptada generalmente por los ciudadanos y por tanto el seguimiento y desarrollo de algunas de ellas por parte del Estado a través de las instituciones

${ }^{13}$ P.R.I.G., págs. 259-260. Ver también: T.J., cap. II y VII; J.F.P M.; I.O.C. 
básicas le daría un carácter sectario, no admisible desde un liberalismo político como el de Rawls.

Es en este contexto donde hay que entender la afirmación, o mejor dicho la exigencia, de neutralidad del estado con respecto a las concepciones del bien por parte del liberalismo político rawlsiano y del liberalismo en general.

Para Rawls la noción de neutralidad ${ }^{14}$ es parte de una etapa y le sirve ante todo para conectar la prioridad de lo justo con las dos ideas de bien que hasta ahora hemos venido analizando: bondad como racionalidad y los bienes primarios básicos.

Ahora bien, desde el punto de vista rawlsiano la participación en los bienes primarios no es entendida como la media del bienestar psicológico o utilidad esperada del conjunto de los ciudadanos, como los economistas pueden decir, pues la justicia como equidad rechaza de plano la idea de comparar y maximizar el conjunto del bienestar como tema de la justicia política. Los bienes primarios tan solo especifican las necesidades que los ciudadanos como personas libres e iguales tienen o, lo que es lo mismo, cuál es su bien en cuanto ciudadanos cuando las demandas de justicia se plantean.

Es en ese sentido en el que se puede decir que la concepción rawlsiana de la justicia es neutral, ya que su objetivo central no es defender una concepción general del bien como la única verdadera e imponerla a través de las instituciones sociales básicas, sino estructurar una sociedad libre donde los individuos puedan desarrollarse como personas libres e iguales, tomando como punto de partida la libertad, que es al mismo tiempo el contenido de la justicia.

Todo ello nos lleva a la idea del bien de una sociedad política, más específicamente el bien que los ciudadanos realizan, como personas individuales y como cuerpo corporativo, al mantener un régimen constitucional justo.

Para ello Rawls admite la necesidad de desarrollar en los individuos determinadas virtudes políticas ${ }^{15}$-tolerancia, razonabilidad y el sentido de equidad-, lo que no implica en ningún momento que jus-

${ }^{14}$ P.R.I.G., págs. 260-268. Sobre este tema de la «neutralidad y liberalismo», son muy interesantes los análisis de: Catherine Audard, «Principes de Justice et Principes du Libéralisme: la 'Neutralité de la Théorie de Rawls'», en: C. Audard, R. Boudon et al.: Individu et justice Sociale. Autour de John Rawls, Editions du Seuil, 1988, págs. 158-193: R. Dworkin, A Matter of Principle, Oxford, Clarendon Press, 1986, págs. 191 y ss.; Peter Marneffe, «Liberalism, Liberty, and Neutrality», en: Philosophy and Public Affairs, vol. 19, n. ${ }^{\circ}$ 3. 1990, págs. 253-274; Joseph Raz, The Morality of Freedom, Oxford, Clarendon Press, 1989, págs. 110-133; «Facing Diversity: The Case of Epistemic Abstinence», en: Philosophy and Public Affairs, vol. 19, n. ${ }^{\circ}$ 1, 1990, págs, 3-47.

${ }^{15}$ Sobre este tema de la importancia de las «virtudes públicas», en terminología 
ticia como equidad conciba a la sociedad como una comunidad política al estilo clásico aristotélico, sino más bien como una unidad social de individuos diferentes o grupos distintos que cooperan para conseguir sus propios fines, ya sean individuales o asociativos, y que comparten una misma visión sobre sí mismos.

«Justicia como equidad abandona el ideal de una comunidad política si por aquel ideal entendemos una sociedad política unificada bajo una única doctrina comprehensiva religiosa, moral y filosófica. Esa concepción de la unidad social está excluida por el hecho del pluralismo (...), el liberalismo político concibe la unidad social de una forma diferente -a saber, como derivada a partir de un consenso por solapamiento sobre una concepción política de justicia. En semejante consenso esta concepción política es afirmada por los ciudadanos que mantienen diferentes y conflictivas doctrinas comprehensivas. Esto lo hacen desde el interior de sus propias y diferentes visiones» ${ }^{16}$.

Las virtudes políticas en este sentido se nos presentan como aquellas disposiciones o rasgos del carácter que es necesario desarrollar en las personas en cuanto ciudadanos, porque ello, sin duda, contribuirá a lograr una mayor estabilidad y cohesión social. En suma, las virtudes políticas para Rawls son aquellas disposiciones que, cuanto más desarrolladas estén en los ciudadanos, mejor contribuirán a que la sociedad sea una empresa cooperativa para el beneficio de todos, constituyéndose así en un bien para todos los ciudadanos que la conforman.

Y llegamos, de esta forma, a la última idea de bien inserta en la concepción política de bondad como racionalidad, que nos presenta a la sociedad bien ordenada como un bien a un doble nivel: a) es un bien para las personas individualmente en cuanto que les posibilita el ejercicio de sus dos poderes morales y les asegura las bases sociales de su mutuo respeto; b) es un bien social y político en cuanto que el desarrollo de semejante sociedad es un objetivo que necesita la cooperación social de todos para llevarse a cabo.

La sociedad bien ordenada, en cuanto que un bien social, se realiza a través del esfuerzo continuado de los ciudadanos en mutua dependencia que tratan ante todo de realizar el fin político básico

rawlsiana «virtudes políticas», ver el trabajo de Victoria Camps, Virtudes públicas, Madrid, Espasa-Calpe, 1990, donde, especialmente en las págs. 42-44, se valora positivamente la aportación rawlsiana. Ver también nota (3), P.R.I.G., págs. 263, 272, 274.

${ }^{16}$ P.R.I.G., pág. 269 (el subrayado es mío). Ver también I.O.C. 
que tienen en común, esto es, soportar instituciones democráticas, justas en base a una concepción política de justicia, que es lo único que posibilitará a los ciudadanos el desarrollarse como personas morales, libres e iguales.

Rawls concluye su argumentación señalando que la sociedad bien ordenada es un bien político que tiene una absoluta importancia y significación dentro de una concepción política de justicia, que es el fin último que tienen en común todos los miembros de una sociedad, al asegurar la igualdad de derechos y libertades básicas, la igualdad equitativa de oportunidades, así como el reconocimiento público de las personas como ciudadanos libres e iguales con unos poderes morales que desean ejercitar.

Por tanto, la prioridad de lo justo sobre el bien no significa que las ideas del bien deban ser evitadas, lo que es imposible, sino que, como indica el propio Rawls,

«...las ideas usadas deben ser políticas: deben ser confeccionadas para adaptarse a las restricciones impuestas por la concepción política de justicia y ajustarse al espacio que ésta permite» ${ }^{17}$.

Así, el bien envuelto en el ejercicio de los poderes morales y en el reconocimiento público del estatus de las personas como ciudadanos pertenece, según Rawls, al bien político de una sociedad bien ordenada, y no al bien propio de una doctrina comprehensiva, ya sea religiosa, filosófica o moral. Es en este sentido en el que hay que entender la valoración positiva que el liberalismo político de Rawls hace de la participación activa de los ciudadanos en la vida política y su idea de que, cuanto más estén arraigadas en ellos las virtudes políticas, mejor contribuirán a mantener un régimen constitucional democrático, base de garantía de las libertades democráticas.

La vida política es, por tanto, valorada como parte del bien político y social de los ciudadanos en cuanto que es un medio para la protección de las libertades básicas democráticas, pero no como el bien por excelencia constitutivo de la «vida buena» tal como es interpretado en un aristotelismo, en un humanismo cívico.

La vida política, las instituciones políticas, están dentro del pensamiento rawlsiano al servicio de los derechos fundamentales de los ciudadanos y tienen como objetivo no definir a priori lo que es la «vida buena», sino garantizar un marco constitucional que posibilite a cada individuo o grupo de individuos el ir construyéndose lo que para cada uno es su ideal de «vida buena».

${ }^{17}$ P.R.I.G., pág. 271. 
Como se desprende de las páginas precedentes, en Rawls nos encontramos con las ideas propias del liberalismo clásico junto con una evolución y actualización de las mismas, realzando algunos elementos y mitigando otros e introduciendo algunos nuevos. Frente a esta línea de pensamiento ha surgido una postura crítica, como ya hemos apuntado al comienzo del presente trabajo, que alcanza su máxima expresión en los planteamientos contramodernos de A. MacIntyre, M. J. Sandel y Bellah y en los análisis de Ch. Taylor y M. Walzer que no quieren renunciar a las marcas políticas de la modernidad ${ }^{18}$. Todos ellos, en general, pretenden proporcionar una alternativa al proyecto normativo de la modernidad, al programa racionalista, universalista y liberal de la política de la modernidad.

Como señala $\mathrm{C}$. Thiebaut ${ }^{19}$, conforme el debate comunitarismo -liberalismo se ha ido realizando y progresando ha dejado de ser teórico para tener cada vez más un alcance político. La tensión teórica entre universalidad y particularidad que poseía al principio un carácter epistémico se presenta ahora como tensión política. Ello se debe fundamentalmente a que la reconstrucción liberal rawlsiana y su crítica comunitarista no se entienden ya como posturas enfrentadas sobre la fundamentación de los principios éticos, sino como interpretaciones diferentes de los límites de las sociedades democráticas.

En general los pensadores comunitaristas piensan que no es viable una propuesta ética y política que surja al margen y no se base en la tradición de la polis, en la tradición comunitarista.

Estos autores coinciden en considerar que el liberalismo falla, por un lado, al no tener en cuenta la comunidad como el elemento esencial de lo que constituye la vida buena, con lo que permanece ciego a la valoración de la participación de cada individuo en la comunidad política como un fin fundamental para alcanzar ese ideal de vida buena, de sociedad buena, y por otro, al ofrecernos una visión incorrecta del ser humano, al no tener en cuenta que éste está constituido por valores y compromisos comunitarios que no son de libre elección.

En suma, los pensadores comunitaristas, en su crítica a los programas modernos liberales, comparten determinados supuestos metodológicos:

«...La prioridad de las nociones de bien sobre los acuerdos de justicia, la crítica al yo sin atributos del pensamiento ato-

${ }^{18}$ Ver nota (5). R. Bellah et al., Habits of the Heart, N. York, Harper and Row, 1985 (trad. cast. Hábitos del corazón, Madrid, Alianza Editorial, 1989); M. Walzer, Spheres of Justice. A Defense of Pluralism and Equality, N. York, Basic Books, 1983; «The Communitarian Critique of liberalism», en Political Theory, vol. 18, n. ${ }^{\circ} 1,1990$, págs. 6-23.

${ }^{19}$ Carlos Thiebaut, Los límites de la comunidad, Madrid, C.E.C., 1993, pág. 143. 
mista liberal y la inevitabilidad de los determinantes contextuales e históricos, en forma de valores comunitarios y tradiciones» ${ }^{20}$.

Ahora bien, aunque esos puntos de coincidencia nos permiten situar bajo el rótulo de comunitaristas a distintos autores, no podemos hacerlo sin tener en cuenta los matices que los diferencian. Pues mantienen posturas que van desde planteamientos conservadores y neo-aristotélicos (MacIntyre, Sandel, Bellah) a concepciones neohegelianas y más renovadoras cuya crítica se inserta en el proyecto normativo de la modernidad (Taylor y Walzer $)^{21}$.

En particular M. Sandel y A. MacIntyre ${ }^{22}$ critican el liberalismo político de Rawls, entre otras cosas, por considerar a la justicia como la virtud fundamental de las instituciones sociales: para ellos la justicia es solamente un remedio necesario en aquellas circunstancias en las que la más alta virtud, la comunidad, ha sido destruida.

Sobre esta tríada justicia-bien-comunidad los análisis comunitaristas de Walzer aportan una perspectiva menos neoconservadora y neoaristotélica (quizás más neohegeliana y progresista) que las de MacIntyre y Sandel, pero coincidente con ellos en la no admisibilidad de la prioridad de lo justo sobre el bien y la universalidad de los principios de justicia postulada entre otros por Rawls.

Walzer, en su obra Spheres of Justice ${ }^{23}$, nos aporta una concepción de «justicia distributiva» que parte de concebir a la sociedad humana como una comunidad distributiva. Pues continuamente nos reunimos para compartir, dividir y cambiar bienes. Conjuntamente producimos cosas que cambiamos, dividimos y compartimos.

Por tanto, la idea de justicia walzeriana tiene que ver tanto con ser y hacer como con tener, tanto con producir como con consumir, tanto con identidad y estatus como con capital y posesiones. La justicia afecta, así, a todas las esferas donde se realiza y desarrolla la vida humana.

Ahora bien: para Walzer no hay, ni ha habido, un único punto de acceso al mundo de los acuerdos e ideologías distributivas. Para él nunca ha existido un medio universal de cambio, nunca ha habido un único criterio o un único conjunto de criterios interconectados para todas las distribuciones. Por ello la pretendida universalidad de unos principios de justicia defendida por el proyecto normativo moderno le parece criticable e inadmisible.

${ }^{20}$ C. Thiebaut, ibid., pág. 141. ver también págs. 36, 103, 177.

${ }^{21}$ C. Thiebaut, ibid., págs. 24-25, ver también pág. 141.

${ }^{22}$ M. Sandel, op. cit. y artic. cit.; A. MacIntyre, ops. cits.

${ }^{23}$ M. Walzer, op. cit., pág. 34. 
«...Los principios de justicia son ellos mismos pluralistas en la forma; diferentes bienes deben ser distribuidos en base a diferentes razones; y esas diferencias se derivan desde una comprensión diferente de los bienes sociales mismos -el producto inevitable de un particularismo histórico y cultural» ${ }^{24}$.

Hay una pluralidad de criterios distributivos y lo único que necesitamos para explicar y limitar ese pluralismo es una teoría del bien. Esta teoría, según Walzer ${ }^{25}$, tiene una serie de características: todos los bienes con los que la justicia tiene que ver son bienes sociales; no hay un único conjunto de bienes primarios o básicos concebibles a través de todos los mundos morales y materiales; el criterio distributivo y los acuerdos son intrínsecos para el bien social. Todas las distribuciones son justas o injustas relativamente a los significados sociales de los bienes.

«...No hay un único estándar. Pero hay estándares (fuertemente cognoscibles cuando son controversibles) para cada bien social y cada esfera distributiva en cada sociedad particular» ${ }^{26}$.

Por tanto, para Walzer el sentido social, el significado social, es el principio legitimador de lo justo. Los significados sociales son históricos en carácter. Las distribuciones justas e injustas cambian en el tiempo, y cuando los significados son distintos, las distribuciones deben ser autónomas. Todo bien social o conjunto de bienes constituye una esfera distributiva dentro de la cual solamente ciertos acuerdos y criterios son apropiados.

La comunidad política es el escenario apropiado para esta empresa. La comunidad es por sí misma un bien -concebiblemente el bien más importante- que se distribuye. La comunidad política es probablemente lo más cercano a un mundo de significados comunes. El lenguaje, la historia y la cultura vienen conjuntamente a producir una conciencia colectiva. La única alternativa plausible a la comunidad política es la humanidad.

«...La cultura de una comunidad es la historia de sus miembros que habla de cómo dan sentido a todas las piezas diferentes de su vida social -y la justicia es la doctrina que distingue las piezas en una sociedad diferenciada. La justicia

\footnotetext{
${ }^{24}$ M. Walzer, ibid., págs. 5-6.

${ }^{25}$ M. Walzer, ibid., págs. 7-10.

${ }^{26}$ M. Walzer, ibid., pág. 10.
} 
hará la armonía sólo si primero hace la separación. Buenas cercas hacen sociedades justas» ${ }^{27}$.

Por tanto, la justicia en Walzer se plantea como el estándar interno que cada sistema social (ya se trate del de casta en la India, el capitalista, etc.) tiene y por el que se rige. La justicia es así relativa al sentido social. No puede haber una sociedad justa, nos dice Walzer

«... hasta que no exista una sociedad, y el adjetivo justo no determina, sino solamente modifica, la vida sustantiva de las sociedades descritas. Hay un número infinito de posibles vidas formadas por un infinito número de posibles culturas, religiones, acuerdos políticos, condiciones geográficas, etc. Una sociedad dada es justa si su vida sustantiva es vivida de una cierta forma -esto es, en una forma fiel a la comprensión compartida por sus miembros» ${ }^{28}$.

De esta forma, la conciencia colectiva, común, la comunidad política, es el principio legitimador de lo justo, y aunque Walzer defienda el pluralismo y la diferenciación, los límites de ésta vendrán impuestos por la comunidad política y la comprensión del bien social que ésta tiene.

Por tanto, Walzer no puede escapar al holismo ontológico propio de las concepciones comunitaristas, claramente opuesto al pensamiento liberal moderno.

Esta valoración de la comunidad también está presente en los autores de Habits of the Heart $^{29}$, que consideran que la estructura profunda de la sociedad liberal es comunitarista, y que la teoría liberal distorsiona esta realidad. La retórica del liberalismo limita nuestra comprensión de nuestros propios hábitos del corazón y no nos da ningún camino para formular las convicciones o creencias que nos mantienen juntos como personas y que nos vinculan juntos en una comunidad.

Todo ello nos lleva a otra de las críticas bastante compartidas por autores como MacIntyre, M. Sandel, Walzer y otros, la reivindicación liberal de la neutralidad del Estado frente a distintas concepciones del bien, un hecho que está íntimamente ligado con la defensa y el reconocimiento de la pluralidad como algo esencial a las sociedades democráticas contemporáneas.

${ }^{27}$ M. Walzer, ibid., págs. 318-9; ver págs. 29 y ss.

${ }^{28}$ M. Walzer, ibid., págs. 312-313.

${ }^{29}$ R. Bellah, op. cit., pág. 21, 290. 
Sandel en concreto no está de acuerdo con la defensa por parte del liberalismo de la neutralidad de la ley con respecto al ethos moral de la sociedad. Para él la ley debe amparar lo que se refiere como bueno en una comunidad dada. El ethos sustantivo de la sociedad justifica la intervención del Estado en la vida privada de los ciudadanos llegado el caso. Para Sandel, en suma,

«... (la cura contra el liberalismo) ha de realizarse sobre una apreciación más fina del papel que juega el discurso moral sustantivo en las discusiones políticas y constitucionales $^{30}$.

Es evidente, por tanto, que en los argumentos comunitaristas que hemos referido, toda idea de justicia está ligada a una idea de bien y que, en definitiva, se da una clara prioridad de la racionalidad teleológica en la comprensión de los problemas prácticos.

Empero, aunque es relativamente obvio que toda sociedad se articula en base a determinada idea de bien común que se comparte por los miembros de esa sociedad, el problema aparece, como plantea Carlos Thiebaut,

«.... cuando se trata de especificar cuál es ese bien en concreto, cuál es su grado de concreción o de sustantividad: si es un bien formal (como los derechos de autonomía de los individuos) o es un bien ligado a prácticas sustantivas de valoración moral (como las conductas que una comunidad considera virtuosas» ${ }^{31}$.

La incompatibilidad entre ambas perspectivas surge cuando se analiza la legitimidad (y no sólo la moralidad) de conductas que la mayoría de la sociedad no comparten o consideran que atentan a la subsistencia moral de esa misma comunidad, y cuando esa comunidad se considera legitimada para perseguir o castigar esas conductas.

En esos casos, los comunitaristas rechazarán la neutralidad de los poderes públicos frente a esas conductas, y propondrán una vigilancia activa de las mismas en defensa de la mayoría moral ${ }^{32}$.

Por el contrario, el liberalismo contemporáneo, y en especial el liberalismo político de Rawls, ha intentado la congruencia entre ambas esferas al interpretar, por un lado, los derechos formales de

${ }^{30}$ M. Sandel, «Moral Argument and Liberal Toleration: Abortion and Homosexuality», en: California Law Review, 77, 2, 1989, págs. 511-538, aquí pág. 522, cfr. en C. Thiebaut, op. cit.

${ }^{31}$ C. Thiebaut, op. cit., pág. 154.

${ }^{32}$ Cfr. C. Thiebaut, ibid., pág. 155. 
una forma no puramente descontextualizada, y por otro, las virtudes como fomento de determinadas cualidades básicas de la convivencia social ${ }^{33}$.

Además hay que observar, como indica $\mathrm{J}_{\text {. }} \mathrm{Raz}^{34}$, que el hecho de que el pensamiento liberal parta de la defensa del individuo no quiere decir que rechace la importancia de la comunidad, sino más bien al contrario, pues el ideal de libertad individual descansa sobre la conciencia de que la individualidad de las personas se expresa precisamente en una forma labrada por las prácticas sociales y a través de su capacidad e inclinación para situarse y relacionarse con otros individuos, lo que implica el reconocimiento de los otros también como individuos autónomos y libres.

Por tanto, el interés por la libertad individual y el reconocimiento de que un importante aspecto de ese ideal es la libertad de las personas para pertenecer a distintos grupos con sus propias creencias y prácticas, junto con la capacidad de estos grupos para prosperar, no implica que el liberalismo sea un pensamiento, una filosofía, que deje al margen la comunidad y no tome en cuenta la importancia de la misma. Así, por ejemplo, Rawls ha buscado justificar las tesis de la política liberal sobre las bases de una perspectiva normativa que incluya no solamente el valor de la autonomía individual, sino también del «well-being» del individuo, admitiendo como un ingrediente importante del mismo la participación en la comunidad y el éxito en perseguir sus fines compartidos.

En suma, la reivindicación liberal de los derechos individuales en vez de obstaculizar, proporciona una valiosa protección para el florecimiento de la comunidad, como indican John Tomas y Allen Buchanan ${ }^{35}$, para quienes si consideramos los derechos a la libertad de asociación, expresión y religión que los liberales defienden, nos encontramos con que esos derechos históricamente han proporcionado un fuerte baluarte en contra de los intentos de impedir la existencia y el florecimiento de distintas comunidades dentro de un Estado Nación. En definitiva, han sido el mejor baluarte contra el totalitarismo. Los derechos individuales facilitan el surgimiento de nuevas comunidades posibilitando, al mismo tiempo, el surgimiento de una relación racional entre ellas.

Thiebaut, op. cit.

${ }^{33}$ Ver sobre este tema M. ${ }^{\text {a }}$ P. González Altable, art. cit. y op cit. cap. IV. Ver también C.

${ }^{34}$ J. Raz, art. cit. Ver también: J. Paul y F. D. Miller, Jr., «Communitarian and Liberal Theories of the Good», en: The Review of Metaphysics, vol. XLIII, n. ${ }^{\circ} 4,1990$, págs. 803-830.

${ }^{35}$ John Tomasi, «Individual Rights and Community Virtues», en: Ethics, vol. 101, n. ${ }^{\circ} 3,1991$, págs. 521-536: Allen E. Buchanan, «Assessing the Communitarian Critique of Liberalism», en: Ethics, vol. 99 , n. ${ }^{\circ} 4,1989$, págs. 852-883. 
En segundo lugar, y con respecto al tema de la justicia, hay que señalar que pensadores como Sandel quizás no han tenido en cuenta, en su análisis crítico de Rawls, que la justicia tiene como objetivo el regular la distribución igual de la libertad junto con los demás bienes básicos aceptados como tales a través de un consenso por solapamiento ${ }^{36}$. Por tanto la justicia no es un remedio sino una condición necesaria para conseguir una comunidad libre y pluralista donde los individuos cooperen en garantizar y desarrollar esos bienes básicos.

Es dentro de este contexto, y en tercer lugar, donde tiene sentido la reivindicación rawlsiana de la neutralidad del Estado con respecto a afirmar la superioridad de una concepción particular del bien frente a otras. Neutralidad que los comunitaristas critican por considerarla como algo imposible de realizar y de poner en práctica. Pero la neutralidad de la que nos habla Rawls ${ }^{37}$ es neutralidad de procedimiento e intención, y no de efecto o influencia, que él mismo rechaza por considerarla impracticable.

Justicia como equidad, en cuanto una concepción política liberal de la justicia, es una concepción neutral en procedimiento e intención, lo que implica:

«... que puede todavía afirmar la superioridad de ciertas formas de carácter moral y alentar ciertas virtudes morales. Por tanto, justicia como equidad incluye una explicación de ciertas virtudes políticas -las virtudes de la cooperación social equitativa tales como civilidad y tolerancia, razonabilidad, y el sentido de equidad $»^{38}$.

Justicia como equidad no busca cultivar otras virtudes y valores distintos de los liberales, de autonomía e individualidad, ni pretende establecer un estado perfeccionista propio de una doctrina comprehensiva, sino más bien favorecer que los individuos desarrollen sus concepciones particulares del bien y las capacidades propias de un buen ciudadano, pues las características de una concepción política de justicia son:

«... 1) que es una concepción moral que trabaja para un objeto específico, a saber, la estructura básica de un régimen

${ }^{36}$ La idea del «consenso por solapamiento» (overlapping consensus) la desarrolla Rawls en sus artículos LO.C. y J.F.P.M. Sobre un análisis más detallado y amplio de este tema, ver: M. ${ }^{\mathrm{a}} \mathrm{P}$. González Altable, art. cit., págs. 45-49, у op. cit., cap. 4.

${ }^{37}$ Sobre el concepto de «neutralidad» y sus distintos tipos, ver J. Raz, op. cit., cap. 5, y R. Dworkin, op. cit., págs. 191 y ss.

${ }^{38}$ P.R.I.G., pág. 263. 
constitucional democrático; 2) que aceptar la concepción política no presupone aceptar una doctrina moral, religiosa, filosófica comprehensiva; ...; y 3) que es formulada no en términos de una doctrina comprehensiva sino en términos de ciertas ideas intuitivas fundamentales vistas como latentes en la cultura política pública de una sociedad democrática ${ }^{39}$.

Todo ello contribuye, según Rawls, a que su liberalismo político supere algunas de las objeciones que suelen plantearse al liberalismo de autores como Kant y Mill.

La sociedad justa liberal, según Rawls, puede tener mayor espacio que otros mundos sociales para admitir distintas concepciones comprehensivas morales, religiosas y filosóficas, aunque, como es evidente, no existe un mundo social que no excluya ciertas formas de vida ${ }^{40}$.

Esta pluralidad, perfectamente admisible dentro de una concepción liberal de la sociedad, es imposible de mantener dentro de otras doctrinas que establecen y defienden una única idea de lo que es un mundo social bueno, que lleva implícito el ideal de una forma de vida buena.

Parece, así, que la crítica central al comunitarismo no es tanto su acento en el carácter histórico y societal de la moral, sino que el supuesto común a dichas posiciones sería una noción homogénea y no compleja de identidad y de comunidad. Esa noción excluiría, precisamente, la complejidad social y las diferenciaciones internas que hicieron necesario institucionalizar con teorías imparciales de la justicia la neutralidad de la esfera pública $^{41}$.

Por tanto, cuando autores como Dworkin o Waldron ${ }^{42}$ se oponen a las tesis comunitaristas, como señala $C$. Thiebaut, no carecen de buenas razones al señalar que el holismo ontológico y el holismo normativo nos dejan sin capacidad de crítica $\mathrm{y}$, consiguientemente, sin dimensión moral. Pues, como expone este autor,

«.... Si una sociedad encuentra en sí misma una fuente moral inagotable de

crítica es porque los sujetos morales que viven y ejercen esos valores no se rigen por los valores morales socialmente dominantes, aunque empleen el lenguaje de su

${ }^{39}$ P.R.I.G., pág. 252. Ver también J.F.P.M., sección I.

${ }^{40}$ P.R.IG., págs. 266-267.

${ }^{41}$ Cfr. C. Thiebaut, op.cit. pág. 161.

${ }^{42}$ R. Dworkin, «Liberal Community», en: California Law Review, 77, 3, 1989, págs. 479-504; J. Waldron, «Particular Values and Critical Morality», California Law Review, 77, 2, 1989, págs. 561-589. 
cultura moral para expresar cómo esos valores otros trascienden el contexto. Y si así es, esa cultura moral que comporta la posibilidad de valores que la trasciendan y la critiquen será una cultura en la que la validez de los principios no se reduce a su vigencia histórica, como es, de hecho, la cultura democrática occidental que está constituida por 'la tradición del cambio, la diversidad, la controversia y la reflexión'» ${ }^{43}$.

De esta forma, podemos señalar, siguiendo a C. Thiebaut, que ni siquiera comunitaristas más progresistas como Taylor y Walzer han logrado superar el holismo ontológico que descansa sobre un supuesto que cabe denominar el «contexto homogéneo de definición comunitaria del bien». Pues, aunque dichas propuestas no carecen ni de lógica interna ni de coherencia, no han tenido en cuenta aquello que es el punto de partida del planteamiento liberal, esto es, la idea de que ya no existen comunidades internamente homogéneas y que, por consiguiente, no cabe plantear la identidad de los sujetos morales como si fueran sujetos sólidamente vinculados a un conjunto de creencias dadas. Y aunque Walzer parece admitir en sus últimos escritos la diferenciación y pluralidad de mundos morales y realzar el papel de la justicia distributiva, su noción densa y homogénea de comunidad como sujeto de valoraciones sustantivas no permite discrepancias internas ni la coexistencia en un mismo espacio político y cultura de sistemas y creencias diversas ${ }^{44}$.

Por ello, junto a la noción homogénea de comunidad del comunitarismo, surge un segundo problema grave de esas reflexiones, como señala $\mathrm{C}$. Thiebaut:

«...El franco etnocentrismo de ese proyecto reconstructivo de las identidades colectivas y nacionales en un mundo cada vez más "simultáneo" y crecientemente consciente de ello. Ese reto es quizás el que debiera hacernos ir más allá de los límites de las teorías liberales, pero no parece que las reflexiones comunitaristas democráticas indiquen pasos a dar en esa dirección» ${ }^{45}$.

Podemos concluir que las críticas comunitaristas, si bien han supuesto un desafío para el pensamiento liberal contemporáneo, para el proyecto normativo de la modernidad, no han estado muy acertadas en sus análisis de concepciones liberales como la de Rawls, que

${ }^{43}$ C. Thiebaut, op. cit., pág. 160.

${ }^{44}$ Cfr. C. Thiebaut, ibid., págs. 161-162.

${ }^{45}$ C. Thiebaut, ibid., págs. 168-169. 
ha mostrado que el liberalismo político contemporáneo puede incorporar algunas de las críticas comunitarias sin renunciar a sus postulados básicos -la defensa de la libertad, la reivindicación de los derechos individuales, la pluralidad y la tolerancia.

Al mostrar que, dentro de su concepción de justicia como equidad, las dos nociones básicas de justicia y bien son perfectamente compatibles y complementarias, Rawls ha proporcionado una teoría normativa que intenta establecer una fundamentación ética de la democracia. Esta teoría presupone un conjunto de valores comunes que las instituciones deben garantizar y define un modelo de sociedad justa donde la cooperación entre todos los individuos es necesaria para su mantenimiento, desarrollo y estabilidad. Pues, como expone C. Thiebaut:

«... la conciencia de las diferencias no implica sólo ya aquel primer nivel de diferenciación con el que el siglo XVI -las diferencias de creencias religiosas y el descubrimiento de nuevos mundos- ni tampoco sólo al segundo nivel de diferenciación al que se está enfrentando la sociedad norteamericana y europea del siglo XX -las diferenciaciones étnicas y culturales en el seno de un mismo espacio político-, sino que esa conciencia de la diferenciación se refiere ya el entendimiento de culturas y tradiciones políticas y morales diversas. La humanidad culturalmente diferenciada de finales del siglo XX empieza a ser consciente de que comparte ya un único espacio de problemas que han de ser enfrentados cooperativamente para solventar la supervivencia misma de la especie. Una conciencia más global del destino colectivo de la humanidad hace presente un único espacio cultural y político diferenciado en el que no domina ya un único lenguaje» ${ }^{46}$.

Es en este contexto donde hay que valorar la propuesta rawlsiana, que, a través de su teoría de justicia ${ }^{47}$, nos muestra la posibilidad de desarrollar un pensamiento político liberal que presupone, por un lado la autonomía y libertad del individuo como un valor moral y político, y por otro, a la sociedad como una empresa cooperativa para el beneficio de todos.

${ }^{46}$ C. Thiebaut, ibid., pág. 169

${ }^{47}$ Sobre la importancia de una teoría de la justicia como parte ética central de la filosofía jurídico-política y su relación con una teoría de la legitimidad política, ver la obra de E. Díaz, Ética contra política. Los intelectuales y el poder, Madrid, C.E.C., 1990; y De la maldad estatal y la soberania popular, Madrid, Debate, 1984. 
En esta línea de análisis son también loables los esfuerzos de pensadores liberales como D. Gauthier, que en su obra Morals by Agreement ${ }^{48}$ concibe a la sociedad justa como un modelo de sociedad que proporciona a sus miembros un esqueleto para una comunidad que no es comunal, y que promueve una socialización encaminada a facilitarles la realización de su autonomía.

Todo ello muestra la vitalidad que en sí mismo encierra el proyecto liberal moderno, al poseer una capacidad reflexiva y crítica que le permite superar sus contradicciones y avanzar hacia la realización de sus ideales de autonomía, libertad, tolerancia y solidaridad.

${ }^{48}$ D. Gauthier, Morals by Agreement, Oxford, Clarendon Press, 1986. 